\title{
Traduire
}

Une autre perspective sur r tr traduction

Revue française de la traduction

$235 \mid 2016$

Luxe, mode... et traduction !

\section{Du diamant au garde-temps}

Noëlle Brunel

\section{(2) OpenEdition}

\section{Journals}

Édition électronique

URL : https://journals.openedition.org/traduire/857

DOI : 10.4000/traduire.857

ISSN : 2272-9992

\section{Éditeur}

Société française des traducteurs

Édition imprimée

Date de publication : 1 décembre 2016

Pagination : 83-84

ISSN : 0395-773X

\section{Référence électronique}

Noëlle Brunel, « Du diamant au garde-temps », Traduire [En ligne], 235 | 2016, mis en ligne le 01

décembre 2018, consulté le 05 juillet 2021. URL : http://journals.openedition.org/traduire/857 ; DOI :

https://doi.org/10.4000/traduire.857 


\section{Du diamant au garde-temps}

\section{Noëlle Brunel}

Au cours d'une carrière par ailleurs assez lisse, il m'a été donné d'effectuer des traductions pour la joaillerie haut de gamme. Mes yeux ont brillé devant les photos à paraître en regard des articles, une légère excitation m'a prise à l'idée de traduire ces communiqués de presse pour tel ou tel nom si prestigieux. Mais tout cet enthousiasme est vite retombé lorsqu'il a fallu étudier le texte de plus près. Qu'il est difficile de décrire la manière dont une pierre précieuse est taillée, puis montée d'une certaine façon, afin de lui donner tout son éclat sans pour autant dévoiler un secret de fabrication bien gardé ! Car, le plus souvent, l'idée d'un communiqué de presse est de porter une nouveauté à la connaissance du public, sinon pourquoi l'écrire ? Et cette nouveauté doit être présentée comme s'il s'agissait d'une invention révolutionnaire dans le domaine, ce qu'elle est parfois. Mais attention à ne pas trop en dire pour éviter que la concurrence ne vienne la copier, surtout si cette invention n'est pas encore protégée !

Que de circonvolutions ne faut-il pas imaginer, que de qualificatifs élogieux, voire dithyrambiques, ne faut-il pas rechercher pour restituer le texte, avec authenticité mais sans emphase. En dépit de ces écueils, le plaisir que j'avais à peaufiner mon texte était pourtant réel. La passion pour mon métier prenait alors tout son sens, le temps passé n'était plus compté, il fallait juste que l'article soit plaisant à lire et l'amateur fortuné tenté d'aller voir de plus près ce fameux bijou qui avait coûté tant d'efforts à tout un panel de professionnels : le créateur qui dessine le modèle, le modeleur qui, en plusieurs étapes, transforme celui-ci en une matrice où sera coulé le métal précieux avant que l'orfèvre n'y sertisse, avec précision, les pierres taillées que le diamantaire aura au préalable soigneusement sélectionnées. Chaque bijou était quasiment une création originale, dupliquée à très peu d'exemplaires, et chaque collection, dont le thème était choisi avec recherche, devait en être le reflet irréfragable.

C'était il y a une décennie environ et lorsque je relis les textes de l'époque, je reste époustouflée de la créativité linguistique dont faisaient déjà preuve les responsables en marketing et en communication. Car, peu importe le moment, rien ne change au pays de la promotion mercantile. 
Article de luxe somptueux ou produit de grande consommation banal, tout l'art consiste à en souligner le caractère prometteur et parfois prétendument novateur, celui-là même que nos aînés, dans leur grande sagacité, avaient déjà su déceler. Telles se prescrivent les tendances, elles-mêmes à l'origine d'une mode qui revient selon un cycle dont le mystère reste à percer. D'ailleurs, dans le secteur du textile par exemple, certains anciens métiers d'art, dont la technique ne s'acquiert qu'au prix d'un long apprentissage sous la tutelle d'un maître, ne sont-ils pas remis en lumière par les grands couturiers afin de rendre leurs défilés encore plus fastueux?

Plus récemment, m'ont été confiées quelques traductions pour l'horlogerie haut de gamme dans lesquelles il fallait vanter les atouts de ces prestigieux garde-temps (terme ancien joliment remis à l'honneur...). Mais si, vous savez bien, ce que vous comme moi appelons communément une "montre ". II faut dire que la complexité technique n'est pas en reste pour fabriquer ces objets de grand luxe. Jugez-en seulement avec un mot tout simple, "chaton ", ainsi défini dans un dictionnaire spécialisé : bague métallique dans laquelle est fixé le rubis qui sert de coussinet au pivot. Or, la moindre des choses pour un traducteur ou une traductrice étant de comprendre un minimum de la technique concernée dans le texte il m'a donc fallu aller voir ce que recouvrait le mot coussinet dans un tel contexte. Voilà comment j'ai appris qu'il s'agissait d'un trou de pivotement ménagé directement dans la platine en laiton, où se meut un pivot en acier du train de roues ou de l'échappement, ce qui n'était pas autrefois sans poser de problèmes de friction, qui ne furent résolus que par Nicols Fatio, lequel eut l'idée d'utiliser des rubis en guise de coussinets. Comme cette définition m'a quelque peu laissée sur ma faim, je me suis empressée d'aller vérifier les explications données pour échappement et rubis, dont je vous épargne ici les définitions tout aussi savantes.

À dire vrai, pour ces projets-là, le rapport temps passé/nombre de mots traduits resta très faible, mais ma curiosité naturelle fut satisfaite. Et j'avoue même une certaine fierté, sans doute naïve et déplacée, d'avoir rendu une traduction portant sur un produit d'un tel renom, comme si l'éclat de la marque allait laisser son empreinte indélébile sur la professionnelle que je suis.

noelle.brunel@wanadoo.fr 